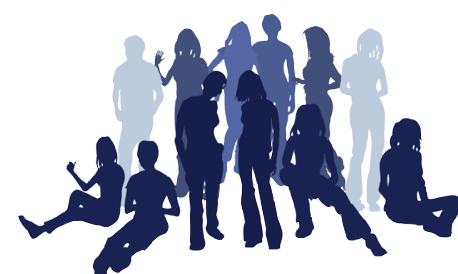

\title{
Treatment Retention Strategies in Transition Age Youth
}

The transition from adolescence to adulthood is a critical window for the development of the adult roles that society relies on: productive worker, nurturing parent, and lawabiding citizen. As they move into adulthood, Transition Age Youth (TAY; ages 17-25) with serious mental health conditions often have poor functioning and high rates of homelessness (30\%), arrests (60\%), school dropout (42\%), and unemployment. ${ }^{1}$ Among outpatient mental health clients, research shows that TAY are consistently the most likely to drop out of treatment ${ }^{1}$ and complete the fewest number of sessions compared to other age groups. ${ }^{2}$ These problems present a unique challenge for keeping TAY in mental health treatment long enough to improve their transition into adult roles.

\section{Improving Treatment Retention for TAY}

Currently there are no clinical trials underway or published treatment retention interventions for TAY. However, there are broad arrays of existing and developing psychotherapies available to the 760,000 TAY who use outpatient psychotherapy each year. ${ }^{3}$ The current research study tests Motivational Interviewing* (MI) as a treatment retention intervention in TAY to determine whether sufficient evidence can be found to justify a full scale clinical trial.

\section{Study Methodology:}

- Study Population - Study population includes TAY recommended for individual psychotherapy after clinical assessment who have no involvement or recommendation for other formal outpatient psychotherapies (e.g. group or family therapy). The study is being conducted at a community mental health center in Central Massachusetts.

- Study Analysis - The primary outcomes are recruitment and retention rates of TAY, as determined by assessing the moderating factors and instrumental goals of the intervention at baseline and at treatment termination or 4 months, whichever occurs first.

\begin{tabular}{|c|c|c|}
\hline Treatment Retention Intervention & Moderating Factors & Instrumental Goals \\
\hline Motivational Interviewing & $\begin{array}{l}\text { - Baseline Motivation to } \\
\text { change } \\
\text { - } \quad \text { Abstract thinking skills }\end{array}$ & $\begin{array}{l}\text { - Increased motivation to change } \\
\text { - Increased self-efficacy } \\
\text { - Strong therapeutic alliance }\end{array}$ \\
\hline
\end{tabular}

\section{Anticipated Contribution to Mental Health Services for TAY:}

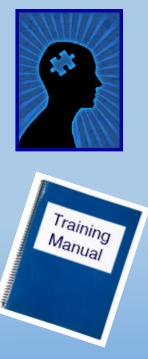

Progress toward retaining TAY in mental health treatments by developing an age-appropriate treatment retention protocol

Developing a manual for training therapists in the Motivational Interviewing-based strategy for treatment retention in TAY and a supervision protocol to ensure treatment fidelity

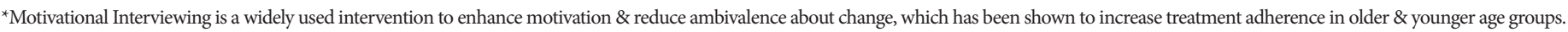

Research Team: Maryann Davis, PhD (Principal Investigator); Charles Lidz, PhD; Lisa Fortuna, MD, MPH; William Fisher, PhD; Lisa Mistler, MD; David Haddad, EdD; Cindy Christiansen, PhD; Ashli Sheidow, PhD. Funder: NIH \# RC1MH088542-01; Time Frame: 2010-2011; Contact: Maryann.Davis@Umassmed.edu 


\section{References}

1. Edlund, M.J., Wang, P.S., Berglund, P.A., Kats, S.J., Lin, E., \& Kessler, R.C. (2002). Dropping out of mental health treatment: Patterns and predictors among epidemiological survey respondents in the United States and Ontario. American Journal of Psychiatry 159: 845-851.

2. Davis, M., Lidz, C., Haddad, D., \& Fisher, W. (under review). Comparing outpatient mental health treatment retention in transition age youth and other age clients of a community mental health center.

3. Olfson, M., Marcus, S., Druss, B., \& Pinkus, H. (2002). National trends in the use of outpatient psychotherapy. American Journal of Psychiatry, I,1914-1920. 